\title{
Variation factors of project plans and their contributions to project failure in Nigeria
}

\author{
${ }^{1}$ E.C. Ubani (Ph.D.), ${ }^{1}$ C.C. Nwachukwu (Ph.D.) and O.C. ${ }^{2}$ Nwokonkwo (Ph.D. Candidate) \\ ${ }^{1}$ Department of Project Management Technology, Federal University of Technology, Owerri- \\ Nigeria
}
2Department of Information Management Technology, Federal University of Technology, Owerri-Nigeria

\begin{abstract}
This study examines and analyses the variation factors of project plan and their contributions to project failure. The slippage of project plans with respect to budget, schedule and quality specifications are indicators of poor performance and imminent failure. The primary data used for the study were captured by field survey on some construction firms based on their experience and perceptions on the subject matter. The methods of multiple regression and correlation analyses were the analytical tools used for the data analysis and statistical test of hypotheses. The results of the analyses indicate that design errors, management problems and resource delivery constraints are the significant variation factors of plan that contribute significantly to project failure. The study therefore recommends evaluation of design effectiveness, prior to project implementation, adoption of material requirements planning principles, and institution of corporate policy for periodic and comprehensive human resources development programmes.
\end{abstract}

Keywords: Variation factors, design errors, cost and time overruns, schedule performance, estimating errors, human resources development, design effectiveness.

\section{INTRODUCTION}

Successful project managers know how important it is to develop, refine and follow plans to meet project goals. It is important to note that the main purpose of project plans is to guide project execution. However, many projects in developing countries usually suffer from slipped milestone, cost and time overruns due to variations in project plans. These could have resulted to stagnated infrastructural and economic development.

Meaningful economic development in Nigeria inevitably requires careful scrutiny of the projects before they are undertaken or implemented. Project implementation is the most resource consuming and visible phase of the project life cycle involving heavy financial outlay. Major modification at this stage could have very serious financial repercussion. Similarly, ineffective project plans and schedule will generally result to escalating investment cost, which could adversely affect the viability of the project. In many economic undertakings, a project would take the form of an investment activity where economic resources are committed to create a productive or earning asset from which one anticipates deriving benefits in future.
Characteristically, economic projects involve sacrifice at one point in time for expected benefits at some later time in future. There have been major constraints and impediments challenging the implementation stage of project life cycle resulting to the variation of the actual progress from the planned progress of project status. If the anticipated variation factors are not properly addressed at the right time, the lofty objectives and desires of project implementation could be a mirage to realize, thus resulting to failure. This study considers it necessary to identify and assess these factors so as to prevent project failure. Also, these variation factors are considered as signals to project failure; and the study is of the view that prevention is better than taking corrective actions. Corrective actions will definitely result to time and cost overruns as well as shoddy reworks.

It could be futile to continue with project implementation after it has already be identified to have deviated from the original schedule, budget and quality specification without re-planning and taking corrective action. However, re-planning of projects and corrective actions could as well result to cost and 
time overruns. Though it may not be possible to completely avoid the negative impact of these variation factors on project implementation, it could be drastically reduced to the barest minimum, as a result of findings from this study. Merely taking corrective action on deviated project plan without analyzing the variation factors and their effects on project failure would not give necessary insight into the problem and would not permit the institution of failure prevention measures. This study is therefore intended to highlight the signals for project failure through identification and analysis of variation factors and address them on time so as to avert or mitigate the adverse effects on the performance of project management.

Since after the Nigerian independence in 1960, many developmental projects have suffered failure and abandonment and hence formed a dog on the wheel of progress. In a depressed economy like Nigeria, both public and private sector projects are vulnerable to failure because of myriad of problems. Even if the resources are available, projects fail due to variations in plans, defective plans and inefficient management. The actual project progress usually deviate from the planned project progress; and as such, much time and resources are expended in tracking down project progress, re-planning, taking corrective actions and bringing back the project progress on course.

Many completed or on-going projects in Nigeria are deficient in performance objectives because; clients and customers are not always satisfied, project time and cost overrun, low quality and shoddy outputs project conflict between the contractors and clients arising from variation in contract sum.

The principal objective of the study is to ensure successful project implementation and completion through the following specific objectives:

* Identify the salient and significant variation factors of project plans, asses their contributions to project failure and address the problems during the feasibility study and planning stages of project life cycle.

* To assess the contributions of aggregate variation factors of project plans to project failure with particular reference to randomly selected failed construction projects in Nigeria.

* To assess the contributions and effects of individual variation factors on project failure.
* To analyze the above results and proffer suggestions and recommendations on the methods of either eliminating or narrowing the gap between project planned progress and project actual progress

The following hypotheses were formulated for the study.

$\mathrm{HO}_{1}$ : Non-availability of resources, design errors/review, technical, management problems etc. are not significant factors to variation of project plan and project failure.

$\mathrm{HO}_{2}$ : Each of the factors such as; non-availability of resources, design errors/review, technical and management problems, etc is a significant factor to variation of project plan and project failure.

The study will serve as a guide and precautionary measure to managers in the planning phase and decision making processes in project management.

\section{THEORETICAL FRAMEWORK}

Variation or deviation from the original project plan could be described as a major case of project failure. Project monitoring and control could only effect corrective actions to bring deviated project plans on course, but failed to take cognizance of identifying and analyzing the root causes of such variations. Also project monitoring and control are not cost and time effective to implement. This study therefore intends to fill these gaps created by project monitoring and control. Oberlender (2000) reports that there is a tendency for some designers to make changes during design in order to please he clients without regard to the impact on these changes on the project cost and schedule. He also says that changes can be catalogued as either project development or scope growth. Project development relates to changes that are needed to accommodate the scope as currently defined scope growth relates to changes that alter the projects original scope; the scope that was approved before starting the design process. These changes, though inevitable usually add cost and time to the original design. The usual practice is that the lead designers must develop a system of monitoring the design effort to ensure that work is progressing without excessive billable hours, but is still producing adequately defined plans and specifications for the contractors to execute the work during construction. Though this will reduce construction contractors complaints of pretty 
drawings that are full of error and lack constructability, they will still add to cost and time of the project. This study favours identifying the salient factors responsible for scope growth and other variations in plans, address them accordingly before the final project design with a view of mitigation or eliminating the negative impacts. It is therefore imperative that every propose change must be subjected to a formal review and approval process that considers cost and schedule implications as well as the quality specification and standards; plus consequential effects on other activities. The authority to approve changes during design must be limited. It is a fact of life that changes and variations in plans occur during the implementation stages of projects and they might result to project failure if not properly rectified. It is believed that project managers need to be ready always to address the problems.

The earned-values system presented by Oberlender (2000) can be determined by multiplying the percent complete times the budgeted designed hours for each task. The earned-value can be compared to actual design-hours billed to the job and the planned design-hours to measure the performance of the design process.

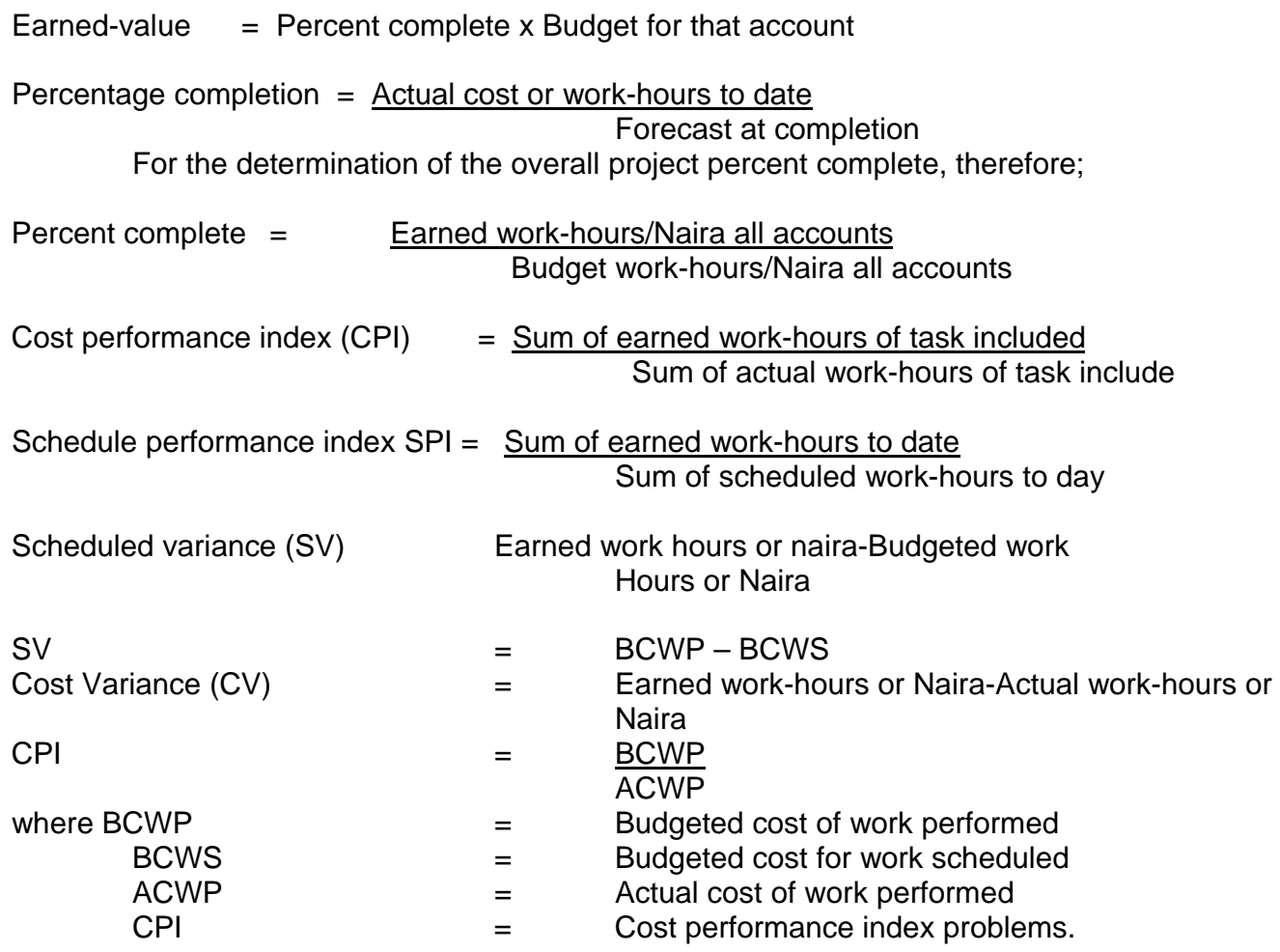

The original cost estimate is the budget actual cost (BAC) in the earned-value analysis. Therefore, if the original cost estimate for the project is incorrect, then all progress measurements during execution of the project would be measured against an incorrect budget. The system of recording costs charged against the job must be consistent to provide realistic comparisons from one reporting period to another.

Also the method of measuring work completed must be consistently applied from one reporting period to another, otherwise the predicted status of the job will vary widely. Each project must be assessed based on the unique circumstance and conditions that apply to the project in order to use the earned-value system to manage the project. The partial list of items that can cause the cost or schedule to vary from the original project plan are presented by Oberlender (2000) as follows: estimating errors, technical problems, design errors, test data problems, constructability and equipment problems, scope control (change orders), management problems, personnel skill level, resource availability organization structure, economic/inflation, delay material deliveries, delay equipment deliveries, poor production rates, subcontractors interference and delay, act of God (weather, fire, flood etc). Telsang (2004) also observes that the following affects plan; 
non availability of materials due to shortages or late delivery, plant, equipment and machine breakdown, change in demand, design and rush orders, absenteeism of workers, and lack of communication among various functional areas of business.

In a similar vein, variation factors of quality plans are usually described as assignable variation. According to Stevenson (2002), unlike natural variation, the main sources of assignable variation can usually be identified (assigned to a specific cause) and eliminated. He further states that; tool wear, equipments that needs adjustment, defective materials, human factors (carelessness, fatigue, noise and other distractions, failure to follow correct procedures and so on) and problems with measuring devices are typical sources of assignable variation.

\section{LITERATURE REVIEW}

\section{(i) PROJECT PLAN}

It is expected that project implementation progress status would to a considerable extent conform to the project plan for successful performance. The project control procedures could therefore come into play to address the problems of deviation in the variation of project plan if any. The plan involves all the necessary details-designs, materials, equipments etc. for the accomplishment of the task/project under consideration. (Akpan and Chizea 2002). The critical project risk potentials in Nigeria, and possible source of concern to lenders, apart from inadequate scope descriptions and documentations are the ever present possibility that the project might not be executed as planned or projected. The forecasted operational profile, market demand, and the like might not be attained thus creating difficulties and bottlenecks in the planned debt service arrangement etc. For a plan to be effective, it must be explicit, intelligible, capable of accepting changes and capable of being monitored. Without good planning, effective project implementation may be impossible and without addressing the variation factors of plan, project failure is imminent. The project planning involves the process of preparing for the commitment of resources in the most economical manner. The planning defines the activities and actions, time and cost targets, and performance milestones which will result in successful project implementation and achievement of project objectives. (Telsang 2004). The plan must indicate the materials, equipment, facilities, human resources and other resources that are necessary to complete the project. The mere fact that one has devoted great resources and time on the planning process and had hopefully come up with what meets the criteria of an effective plan, does not necessarily guarantee that when the plan is put into action, it would automatically achieve the desired goal. Fact of life hardly work that way, the unexpected too often happen irrespective of how meticulous the planning process might have been. Though Akpan and Chizea (2002) are of the view that control provides management with the litmus paper to immediately detect when the expected starts to show signs, this study is of the view that waiting for the moment unexpected starts to show signs and taking corrective actions could lead to waste of time and resources. And as such, identifying such variation factors of project plans on time, and preventing or mitigation their negative effects before they occur in project implementation stage could be an improvement on the existing control system mechanism.

Telsang (2004) also states that the main objective of monitoring is to ensure that various time and cost targets are met and the network as well as its operational plans prepared for execution of projects are adhered to; it may be too late to avoid time and cost overruns associated with corrective action. However, if the variation factors are detected and taken care of during the project appraisal and planning stages, reasonable time and resources could be saved, and project success would be assured. By instituting the control mechanism or milestone is not enough because it only addresses or corrects the defects of variations in plan; which may be costly and time consuming to correct. The basis of project planning is scheduling. Scheduling could be described as list of time certain things happen, a time table, a time plan for a project or simply a list of detailed time table. Akpan and Chizea (2002) describe scheduling as a time phased plan. The main objective of scheduling is to produce time table for individual activities following the plan. Also, cost estimation, cost breakdown structure, budgeting and budgetary control try to ensure; efficient allocation of financial resources to project activities and ensure financial discipline. Irrespective of the above approaches, both actual activity schedules and budget still deviate from the plan. The variation factors used in this study are based on the literature review and information gathered from Oberlender (2000), Telsang (2005) and Chitakara (2006) on variation factors of plans. The identified variation factors of project plans have been broadly classified into the following categories by this study. 


$* \quad$ Management problem
$\quad$ Estimating errors
$\quad$ Resource availability constraint
$\quad$ Technical problem
$\quad$ Design errors.

All the factors were analysed in relation to their effects on the failure of some randomly selected failed projects. The main goals or objectives of a project could be enumerated as: completion on the schedule, within the budgets cost, in compliance with both the quality and functional requirements.

Any project that fails to meet these goals and objectives is a "failed project". According to Chizea (1991), a project has failed if any or a combination of the following anomaly happens:- cost overrun, time overrun, contractor not making a profit, quality of completed project unsatisfactory, project abandoned and not realized.

It is obvious that the fight against project abandonment and failure would not be successful unless one knows in advance the causes of these problems. To ensure that projects are successful and result oriented, a systematic approach to identifying and analyzing causes of variation of project plans, failure and abandonment are necessary.

\section{(ii) VARIATION OF PROJECT PLANS AND PROJECT CONTROL}

Kress (1994) asserts that the primary objective of project management is to meet or exceed the expectations of the sponsors of the project. These expectations are typically expressed within three categories.

* Quality: Project produces desired outcome with minimum defects.

* Cost: The project produces desired outcome for the anticipated cost.

* Schedule: The project produces the desired outcome within the anticipated time frame.

According to Kress (1994) every project should evolve to meet a customer's expectations in all three categories. However, many forces intervene and attempt to push projects off course.

It is therefore essential to manage effectively the projects through proper planning, scheduling and control as project requires a heavy investment and is associated with risks and uncertainties (Telsang 2005). It is a fact that in practice, a well formulated plan usually have inbuilt control mechanism to ensure that all necessary guidelines are in place to enhance success based on the plan. Control mechanism ensures that actions intended to implement established plan to action are compatible with set objectives, and capable of realizing the plan. It could be a problem for a project manager to immediately identify that he is about to exceed a budget and that time and cost overruns are in place as these are later indicated by the control mechanism. However, it could be too late, costly with enormous damages to project performance as these result before the control milestone could signal out of or indicates that there are these variations from the original plan. According to Akpan and Chizea (2002), a control system is normally put in place during the planning process so as to compare actual performance during the plan implementation, with the established planned standard. In a nutshell, the system entails the physical comparison of actual performance with predetermined standards. If performance differs form the established goals, corrective action is immediately put into effect. On the other hand, project execution is the act of putting a project plan into action and simultaneously tracking the effectiveness of the plans in the attainment of the set objectives and this could be described as project control in action. The function has to be defined as the periodic preplanning of the remainder of a project at any point in time based upon current realities and revised expectations. This is understandable as the constraints and even objectives of a project can change during execution. Control is a follow-up to a plan. It is not always easy or possible to detect deviation from plans. It could be on this premise that Akpan and Chizea (2002) assert that planning must be sufficiently detailed to make control feasible, as it readily loses its usefulness if deviation from it cannot be readily detected and corrected. Discrepancies between planned action and reality are expected, to the extent that what is really of real importance is the ability to have access to reasonable corrective action and timely information as the plan implementation progresses instead of insistence on having a perfect plan; which hardly exists. However, it is believed that identifying and analyzing the variation factors of project plan would be able to either eliminating or minimizing the variation gap. Project control especially where wide gap exists between actual and plan is a costly, and time consuming process. Making project events conform to plan is accomplished through the following sequential actions; tracking, reporting and documentation of project progress, comparing of observed actual progress, in terms of cost, time and quality specifications. Similar variations are observed 
in production management. However, these actions could be costly, time consuming and hardly corrected effectively.

According to Telsang (2004); in production planning and control; inspite of planning to the minute details, yet always, (most of time) it is not possible to achieve production 100 percent as per plan. There may be innumerable factors which affect the production system and because of which there is a deviation from the actual plans. These factors could also affect project plan for achieving 100 percent as per plan. Some of the factors identified by Telsang (2004) that affect plans are being referred here once more as;

i) Non availability of materials due to shortages or late delivery.

ii) Plant, equipment and machine breakdown

iii) Change in demand, designs and rush orders

iv) Absenteeism of workers

v) Lack of communication between various functional areas of business. He concludes that if there is a deviation between actual production and planned production, the control function comes into action. Production control through control mechanism tries to take corrective action to match the planned with actual production target. Thus production control reviews the progress of work, and takes corrective steps in order to ensure that programmed production takes place. This study asserts that prevention is better than corrective action, because many corrective actions involve huge financial expenses and take too much of time to correct.

Oberlender (2000) uses earned-value system to identify the magnitude of cost and schedule deviations from the original project plan. However, he did not identify the causes of these problems. Also Table 1: Result of Analysis the causes of deviation in quality plan were not stressed knowing fully well that quality is one of the major performance objectives in project management.

\section{METHODOLOGY AND DATA ANALYSIS}

The study adopted field survey and personal interview with the target respondents/stakeholders in randomly selected failed, on-going and completed projects within the South East Geographical Zone of Nigeria. The data was generated with the instrument of questionnaire modeled in Likert five point scales. The questionnaire was properly designed and standardized in such a way that it captured the attitude and opinion of the target respondents on the subject matter. A total of $54(83 \%)$ target respondents returned their completed questionnaires out of 65 $(100 \%)$ that was distributed to them. Multiple regression and correlation analyses were the analytical tools used for the data analysis and test of research hypotheses with the aid of computer software (SPSS).

\section{TEST OF RESEARCH HYPOTHESES}

$\mathbf{H O}_{1}$ : Management problems, estimating errors, resource availability constraints, technical problems and design errors are significant factors of project plans that contribute to project failure.

$\mathbf{H O}_{2}$ : Each of the salient variation factors of project plan does not contribute significantly to project failure.

These two null hypotheses were test at 5\% level of significance. F-ratio test and t-test were used for $\mathrm{Ho}_{1}$ and $\mathrm{Ho}_{2}$ respectively. Based on the decision rule, if their respective p-value (sig) (see tables 4 and $5)$ are less that $5 \%(0.05)$, the two null hypotheses will be rejected in favour of the alternative hypotheses and vice versa.

Descriptive statistics

\begin{tabular}{|l|c|c|c|}
\hline Factors/variables & Mean & $\begin{array}{c}\text { Std } \\
\text { Deviation }\end{array}$ & Sample size \\
\hline Success level of TQM implementation & 40.19 & 2.190 & 54 \\
\hline$X_{1}$ Management problems & 17.70 & 2.043 & 54 \\
\hline$X_{2}$ Estimating errors & 19.24 & 3.059 & 54 \\
\hline$X_{3}$ Resource availability constraints & 18.85 & 1.607 & 54 \\
\hline$X_{4}$ Technical problems & 17.13 & 1.683 & 54 \\
\hline$X_{5}$ Design errors and review & 17.19 & 2.614 & 54 \\
\hline
\end{tabular}


Table 2: Correlations Matrix

\begin{tabular}{|c|c|c|c|c|c|l|}
\hline & $\begin{array}{l}\text { Project } \\
\text { failure index }\end{array}$ & $X_{1}$ & $X_{2}$ & $X_{3}$ & $X_{4}$ & $X_{5}$ \\
\hline Pearson Correlation:Project failure index & 1.000 & .805 & .404 & .721 & .157 & .867 \\
\hline $\mathrm{X}_{1}$ & .805 & 1.000 & .419 & .544 & .027 & .696 \\
\hline $\mathrm{X}_{2}$ & .404 & .419 & 1.000 & .272 & .164 & .322 \\
\hline $\mathrm{X}_{3}$ & .721 & .544 & .272 & 1.000 & .133 & .712 \\
\hline $\mathrm{X}_{4}$ & .157 & -.027 & .164 & .133 & 1.000 & .001 \\
\hline $\mathrm{X}_{5}$ & .867 & .696 & .322 & .712 & .001 & 1.00 \\
\hline $\mathrm{X}_{1}$ & & .000 & .001 & .000 & .128 & .000 \\
\hline $\mathrm{X}_{2}$ & .000 & & .001 & .000 & .423 & .000 \\
\hline $\mathrm{X}_{3}$ (1. tailed) Project failurex & .001 & .001 & & .023 & .118 & .009 \\
\hline $\mathrm{X}_{4}$ & .000 & .000 & .023 & & .169 & .000 \\
\hline $\mathrm{X}_{5}$ & .128 & .423 & .118 & .169 & & .495 \\
\hline
\end{tabular}

Table 3: Model Summary

\begin{tabular}{|l|c|c|c|c|c|}
\hline Model & $\mathbf{R}$ & $\begin{array}{c}\mathbf{R} \\
\text { Square }\end{array}$ & Adjusted & $\begin{array}{c}\text { Std. Error of the } \\
\text { Estimate }\end{array}$ & Durbin Walson \\
\hline 1 & $.935^{\mathrm{a}}$ & .874 & .861 & .818 & 1.434 \\
\hline
\end{tabular}

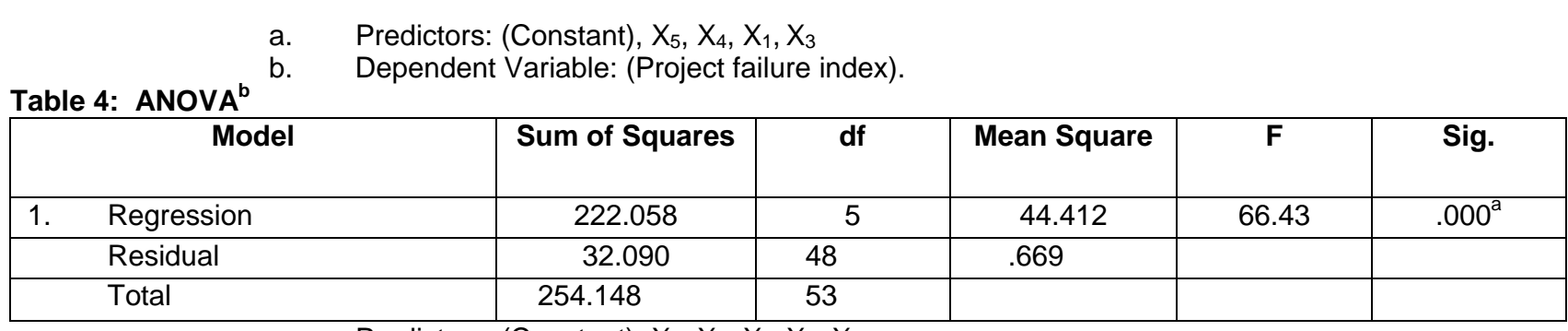

a. Predictors: (Constant), $\mathrm{X}_{5}, \mathrm{X}_{4}, \mathrm{X}_{2}, \mathrm{X}_{1}, \mathrm{X}_{3}$

b. Dependent Variable: (Project failure index).

Table 5: coefficients

\begin{tabular}{|c|c|c|c|c|c|}
\hline \multirow{2}{*}{ Model } & \multicolumn{2}{|c|}{$\begin{array}{c}\text { Unstandardized } \\
\text { Coefficients }\end{array}$} & $\begin{array}{c}\text { Standardized } \\
\text { Coefficients } \\
\text { Beta }\end{array}$ & Sig. \\
\cline { 2 - 5 } & B & Std Error & & 10.001 & 000 \\
\hline Constant & 18.142 & 1.814 & 0.355 & 4.751 & 000 \\
\hline$X_{1}$ & 0.381 & 0.048 & 0.086 & 1.501 & 0.140 \\
\hline$X_{2}$ & 0.062 & 0.041 & 0.086 & 1.501 & 0.140 \\
\hline$X_{3}$ & 0.062 & 0.041 & 0.123 & 1.638 & 0.108 \\
\hline$X_{4}$ & 0.168 & 0.102 & 0.505 & 5.867 & 000 \\
\hline$X_{5}$ & 0.423 & 0.072 & & & 0 \\
\hline
\end{tabular}

b. Dependent Variable: (Project failure index).

Table 6: Significant Ranking of Factors.

\begin{tabular}{|l|c|l|l|}
\hline Factors & t-value & p-value & \multicolumn{1}{|c|}{ rank } \\
\hline Design Errors $\left(X_{5}\right)$ & 5.867 & 000 & 1st (Significant) \\
\hline Management problems $\left(\left(X_{1}\right)\right.$ & 4.751 & 000 & $2^{\text {nd }}$ (Significant) \\
\hline Resource availability problems $\left(X_{3}\right)$ & 3.107 & 0.003 & 3rd (Significant) \\
\hline Technical problems $\left(X_{4}\right)$ & 1.638 & 0.108 & 4th (not Significant) \\
\hline Estimating errors $\left(X_{2}\right)$ & 1.501 & 0.140 & 5th (not Significant) \\
\hline
\end{tabular}




\section{DISCUSSION OF RESULTS}

The predictive regression model of the study is given as

$y=18.142+0.381 X_{1}+0.062 X_{2}+0.215 X_{3}+0.168 X_{4}$ $+0.423 X_{5}$.

The five independent variables indicated a strength of relationship or correlation coefficient $\mathrm{R}=$ $93.5 \%$ and coefficient of determination $\mathrm{R}^{2}$ of $86.1 \%$ to the significant of variation factors and failure index of construction projects. From the $p$ value for F-ratio test, the five independent variables are collective significant and also make significant contribution to project failures. Also, the significance of individual factor and their contribution to project failure from ttest is shown in the ranking table below.

Design errors rank first in the analysis. Design errors lead to in-process design review, constructability problem, scope control and changes, redesign, retest, rectification etc. Schedule and cost performance indices are adversely affected by design errors which could result to time and cost overruns. According to Oberlender (2000), design is a complex process involving application of technical knowledge to create ideas in order to produce a set of specific instruction for construction of the project. He asserts that it is a focal point of definition of the project and has a significant impact on cost and schedule.

Management problems could consist of the following; human resources development constraints, low level of personnel, ineffective organizational structure, subcontractor's interference and delay, all contribute to project failure. Many construction companies hardly invest in human resources development programmes for enhanced capacity building and optimal job performance. Also ineffective organizational structure and incompetent personnel with low skills constrain project success.

A clue from field survey indicates that many project failed due to resource availability constraints such as late delivery of materials, workforce equipment and fund. Also, materials scarcity and poor quality, bottleneck in ordering and importing of equipment, deployment of expatriate manpower to the project site, high cost capital and credit facilities from the financial institution could be classified as resource availability constraint that impede projects progress.

Though the contributions of technical problems and estimating errors are not found to be significant, they could be detrimental to project success if they are not properly managed. It could be that technical problems are usually taken care of during the feasibility analysis of projects. Also, maintenance crew and technical staff are always disposed to face challenges arising from technical problems.

Estimating errors in terms of economic functions, inflation and weather can be forecasted in Nigeria with minimal error. Inflation is always on the increase while force majaure is not common to Nigeria as it rarely occurs to impede project progress.

SUMMARY AND CONCLUSION: Slippage in project plan with respect to cost, schedule, quality and design specifications signals imminent and impending project failure. The result of the data analysis indicates that projects fail due to the contributions significant of variation factors of project plans such as; design errors, and in-process design review, management problems, resource availability constraints, technical problems and estimating errors. The design error and in-process design review contribute most while estimating errors are the least contributors to project failure.

The study therefore recommends that there should be in-depth evaluation of design effectiveness prior to project implementation. The design effectiveness should be analysed based on the following criteria, accuracy, usability, cost, constructability, economy, schedule and start-up (Oberlender 2000). The construction firms should institute a corporate policy for periodic and comprehensive human resources development programmes. To contain and mitigate the problems of resource availability, the principles of material requirements planning should be adopted for scheduled materials delivery. Also, the policy of local content initiative in Nigeria with respect to workforce and raw materials should be vigorously implemented and sustained.

\section{REFERENCES}

Akpan E.O.P. and Chizea E.F. (2002); Project Management; Theory and Practice. FUTO Press Ltd, Owerri - Nigeria.

Chitkara K.K. (1998) Construction Project Management Planning, Scheduling and Controlling. Tata Mc GrawHill Publishing Company, New Delhi.

Chizea E.F. (1991) Application of Network Analysis Techniques to Construction Tendering for the Control of Construction Failures in Nigeria. Unpublished PhD Thesis; Federal University of Technology, Owerri Nigeria. 
Kress R.E. (1994); Quality Project Management: Key Success Factors to Exceeding Buyer Value. www.wrike.com.

Nwachukwu C.C, Echeme, I.I and Okoli, M.N (2010) "Project Management Factor Indexes; A Constraint to Project Implementation Success in the Construction Sector of a Developing Economy" European Journal of Scientific Research" July edition ISSN1450-216X Vol.43 No.3, pp392-405 United Kingdom

Nwachukwu, C.C (2004) "Critical Success Factors for Project Performance in Nigerian Construction Industry", African Journal of Applied and Theoretical Economics (AJATE), Volume 8 No. 2
Nwachukwu, C.C (2009) "Optimization of Design Constraining Factors to Project Management Success of Public and Private Sector Construction in Nigeria (An Analytical Approach)", Interdisciplinary journal of Contemporary Research in Business (IJCRB), Vol.1,No.5 United Kingdom.

Oberlender G.D. (2000) Project Management for Engineering and Construction. Second Edition Mc Graw-Hill, Boston.

Stevenson W.J. (2002) Operations Management; Seventh Edition, Mc Graw-Hill Irwin.

Telsang M. (2004) Industrial Engineering and Production Management. S. Chand and Company Ltd. New Delhi. 